\title{
SISTEM INFORMASI E-RECRUITMENT KARYAWAN BERBASIS WEB PADA PT. JASA SWADAYAUTAMA (JAYATAMA)
}

\author{
Andika Bayu Hasta Yanto ${ }^{1}$ \\ ${ }^{1}$ Sistem Informasi Akuntansi \\ AMIK BSI Tangerang \\ andika.akx@bsi.ac.id
}

\author{
Ahmad Fauzi ${ }^{2}$ \\ ${ }^{2}$ Komputerisasi Akuntansi \\ AMIK BSI Jakarta \\ ahmad.afz@bsi.ac.id
}

\author{
Febri Ainun Jariyah ${ }^{3}$ \\ ${ }^{3}$ Sistem Informasi \\ STMIK Nusa Mandiri Jakarta \\ febryainun@gmail.com
}

\begin{abstract}
Abstrak - E-Rekrutmen penting bagi organisasi karena memiliki fungsi untuk menghimpun sumber daya manusia ke dalam suatu organisasi, kemajuan teknologi yang berkembang telah memaksa perusahaan untuk menerapkan yang namanya e-recruitment yaitu sistem rekrutmen yang memanfaatkan internet. Ada beberapa perbedaan pada sistem ini dibandingkan jika perusahaan menerapkan sistem rekrutmen tradisional, namun perbedaan tersebut bukanlah suatu masalah karena perusahaan dapat memperoleh banyak manfaat dari sistem online ini, yaitu penghematan biaya, kemudahan dalam penggunaan bagi kandidat, kemudahan penggunaan bagi organisasi, meningkatkan kecepatan proses perekrutan dan keberhasilan dalam menemukan calon karyawan potensial.
\end{abstract}

Kata kunci : E-Recruitment, Internet

\section{PENDAHULUAN}

Perkembangan teknologi semakin pesat, perusahaan membutuhkan tenaga kerja yang terampil sehingga dapat membawa perusahaan berkembang dan bersaing dengan perkembangan teknologi, aspek perekrutan karyawan menjadi sangat berpengaruh terhadap kemajuan perusahaan, proses perekrutan yang tidak sesuai dengan kebutuhan perusahaan dapat menghambat perkembangan perusahaan. Demikian juga dengan PT. Jasa Swadaya Utama (JAYATAMA), banyaknya data pelamar yang mengirimkan surat lamaran baik melalui email, kator pos atau dating langsung ke kantor, sangat menyulitkan bagiaan HRD untuk mengecek data pelamar tersebut.

E-Recruitment merupakan sebuah metode perekrutan tenaga kerja yang dilakukan secara online melalui beberapa tahap dari pendaftaran, upload berkas sampai dengan tes psikologi, sehingga membantu HRD dalam menyeleksi karyawan, menghemat waktu serta mendapatkan karyawan yang sesuai dengan kebutuhan perusahaan.

Berdasarkan latar belakang tersebut maka penulis mengambil judul : "Sistem E-Recruitment Karyawan berbasis web pada PT. Jasa Swadaya Utama (JAYATAMA)",

Menurut Setiati (2013:38) Karyawan merupakan aset yang berharga bagi sebuah perusahaan dalam mencapai tujuannya. Fokus utama Manajemen Sumber Daya Manusia (SDM) adalah memberikan kontribusi atas suksesnya perusahaan. Agar produktifitas perusahaan berjalan lancer diperlukan tenaa terja atau karyawan yang sesuai sesuai dengan prinsip "the right man in the
Abstract-Recruitment is important for organization because it has function of collecting human resources toward the organization, the technology development has grown up and it forces Company to apply what is called as e-recuitment which is internet based recruitment. There are some differences in this system compared to traditional recruitment system. However, the difference is not problem because company gain many advantages from the online system, which are cost efficiency, easy-to-use by candidate, easy-to-use by organization, increasing speed of recruitment process and the success of finding potential employees.

\section{Keyword : E-Recruitment, Internet}

right place". Sejalan dengan itu maka langkah awal yang menjadi kunci utama yaitu proses rekrutmen dan seleksi untuk merekrut tenaga kerja sesuai dengan kebutuhannya. Proses seleksi merupakan serangkaian langkah kegiatan yang digunakan untuk memutuskan kandidat (calon karyawan) yang dapat ditempatkan secara tepat.

\section{METODE PENELITIAN}

Metode yang digunakan pada pengembangan perangkat lunak ini menggunakan model Waterfall.

Menurut Sukamto dan Shalahuddin (2015:28) "Model air terjun (waterfall) sering juga disebut model sekuensial linier (sequential linear) atau alur hidup klasik (classic life cyrcle)". Model air terjun menyediakan pendekatan alur hidup perangkat lunak secara sekuensial atau tururut dimulai dari analisis, desain, pengodean, pengujian, dan tahap pendukung (support).

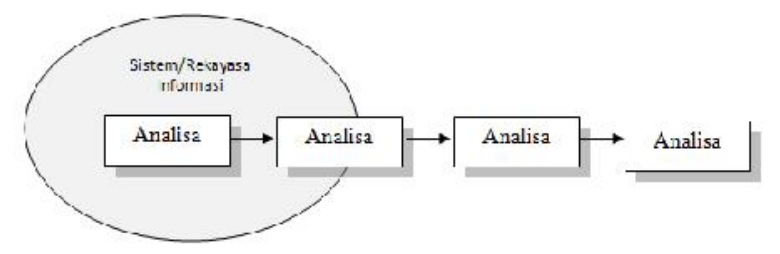

Sumber : Sukamto dan Shalahuddin (2015)

Teori Pendukung

1. UML (Unified Modelling Language) 
Menurut Sukamto dan Shalahudin (2015:137) "UML Merupakan bahasa visual untuk pemodelan dan komunikasi mengenai sebuah sistem dengan menggunakan diagram dan teks-teks pendukung".

Berikut penjelasan tiga diagram UML yang akan di uraikan:

a. Use Case Diagram

Menurut Sukamto dan Shalahuddin (2015:155)

"Use Case Diagram merupakan pemodelan untuk melakukan (behavior) sistem informasi yang akan di buat. Use Case mendeskripsikan sebuah interaksi antara satu atau lebih aktor dengan sistem informasi yang akan dibuat".

b. Activity Diagram

Menurut Sukamto dan Shalahuddin (2015:161)

"Activity Diagram menggambarkan workflow (aliran kerja) atau aktivitas dari sebuah sistem atau proses bisnis. Yang perlu diperhatikan disini adalah bahwa diagram aktivitas menggambarkan aktivitas sistem bukan apa yang dilakukan aktor".

c. Component Diagram

Menurut Sukamto dan Shalahuddin (2015:148)

"Component Diagram dibuat untuk menunjukan organisasi dan tergantungan diantara kumpulan komponen dalam sebuah sistem. Diagram komponen fokus pada komponen sistem yang dibutuhkan dan ada di dalam sistem".

d. Deployment Diagram

Menurut Sukamto dan Shalahuddin (2015:154) "Deployment Diagram merupakan konfigurasi komponen dalam proses eksekusi aplikasi".

\section{2. $\quad$ ERD (Entity Relationship Diagram)}

Menurut Indrajani (2011:11) "Entity

Relationship Diagram adalah sebuah pendekatan dalam perancangan basis data yang di mulai dengan mengidentifikasikan data-data terpenting yang disebut dengan entitas dan hubungan antara entitas-entitas tersebut yang digambarkan dalam suatu model".

Simbol-simbol yang digunakan dalam merancang dengan menggunakan

ERD menurut Indrajani (2011:11) adalah sebagai berikut:

\section{a. Entitas}

Entitas adalah kumpulan objek yang dapat dibedakan atau dapat didefinisikan secara unik.

b. Relationship

Relationship adalah hubungan yang terjadi antara entitas atau lebih.

c. Atribut

Atribut adalah karakteristik dari entitas yang menyediakan penjelasan detail entitas.

d. Link

Link adalah baris penghubung antara himpunan relasi, dan himpunan entitas dan atributnya.

Kardinalitas menunjukan jumlah entity yang dihubungkan ke satu entity lain dengan suatu relationship sets. Kardinalitas meliputi : a. Hubungan satu ke satu (one to one) satu entity dalam A dihunbungkan dengan maksimum satu entity

b. Hubungan satu ke banyak (one to many) Satu entity dalam A dihubungkan dengan sejumlah entity daam entity B dihubungkan maksimum satu entity dalam A.

c. Hubungan banyak ke satu (many to one)

Satu entity dalam A dihubungkan dengan maksimum satu entity B. satu entity dalam B dapat dihubungkan dengan sejumlah entity dalam A.

d. Hubungan banyak ke banyak (many to many) Entity dalam A dapat dihubungkan dengan sejumlah entity dalam B dengan sejumlah entity dalam A.

3. LRS (Logical Relationship Structure)

Menurut Kusrini ( 2007:212) "LRS (Logical

Record Structure) Adalah representasi dari struktur record-record pada tabel-tabel yang terbentuk dari hasil antar himpunan entitas. Menentukan kardinalitas, jumlah table dan Foreign Key (FK)."

LRS (Logical Record Structur)terdiri dari linklink diantara tipe record, link ini menunjukan arah dari satu tipe record lainnya.

\section{Black-Box Testing}

Menurut Sukamto dan Shalahudin (2015:275) "Black-box testing yaitu menguji perangkat lunak dari segi spesifikasi fungsional tanpa menguji desain dan kode program. Pengujian dimaksudkan untuk mengetahui apakah fungsi-sungsi masukan dan keluaran perangkat lunak sesui dengan spesifikasi yang dibutuhkan".

\section{PEMBAHASAN}

\subsection{Tahapan Analisis}

Perancangan Website E-Recruitmen karyawan berbasis web pada PT.Jasa Swadaya Utama sudah terkomputerisasi agar lebih efisien dengan menggunakan beberapa user. Dalam perancangan website ini software yang digunakan yaitu XAMPP versi

1.7.3. sebagai server (localhost), yang terdiri atas Apache HTTP Server, MySQL database dan penerjemah bahasa yang ditulis dengan bahasa pemrograman PHP menggunakan software Adobe Dreamweaver CS 5.5 dan untuk mempercantik tampilan web digunakan software Adobe Photoshop CS3.

Website sistem informasi kebudayaan Betawi yang dirancang memiliki content sebagai berikut:

1. Halaman Admin, terdiri dari halaman login, halaman utama admin atau beranda. Admin dapat melakukan login dapat mengelola data calon karyawan, data karyawan, laporan karyawan, dan melakukan logout.

2. Halaman user, yang terdiri dari halaman utama pengunjung atau beranda, user dapat melakukan login, 
dapat mengelola data diri, mengerjakan soal psikotes, melakukan logout.

. Halaman Siswa, yang terdiri dari halaman utama siswa atau beranda. Siswa dapat melakukan login. melakukan ujian, mencetak bukti ujian.dapat melakukan logout.

\subsection{Desain Sistem dengan UML}

Diagram use case menunjukan interaksi antara usecase dan actor. Diagram ini menggambarkan model lengkap tentang apa yang sekolah lakukan, dan siapa yang berperan dalam erecruitmen karyawan.

1. Use Case Diagram Halaman Index

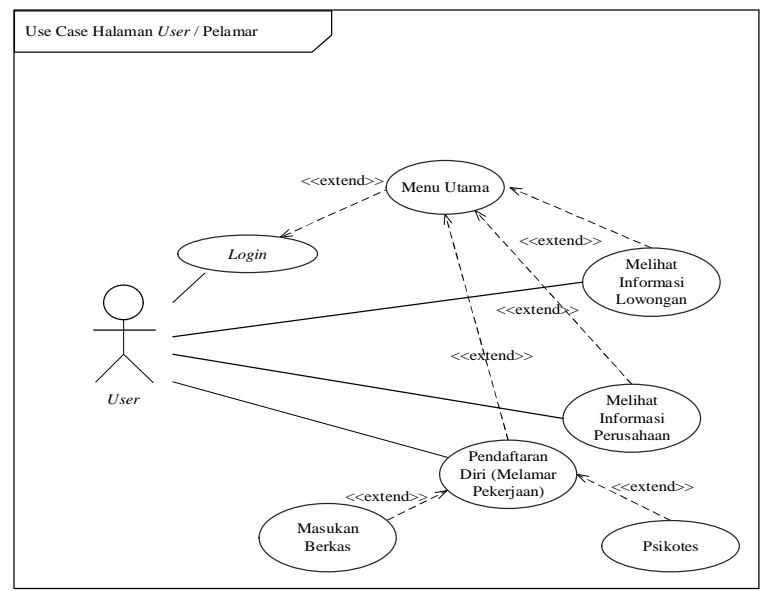

\subsection{Activity Diagram}

1. Activity Diagram pelamar admin

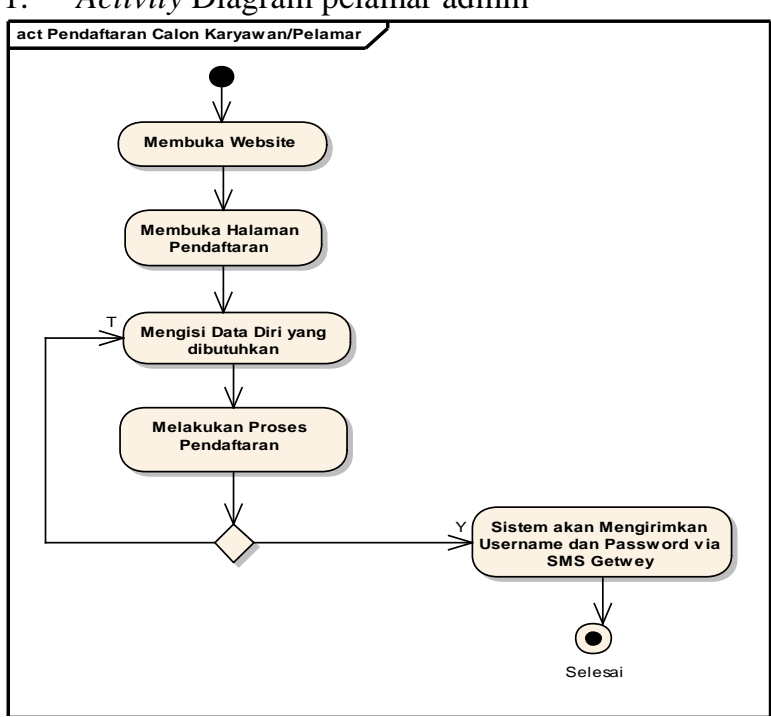

2. Activity Diagram Data Ujian

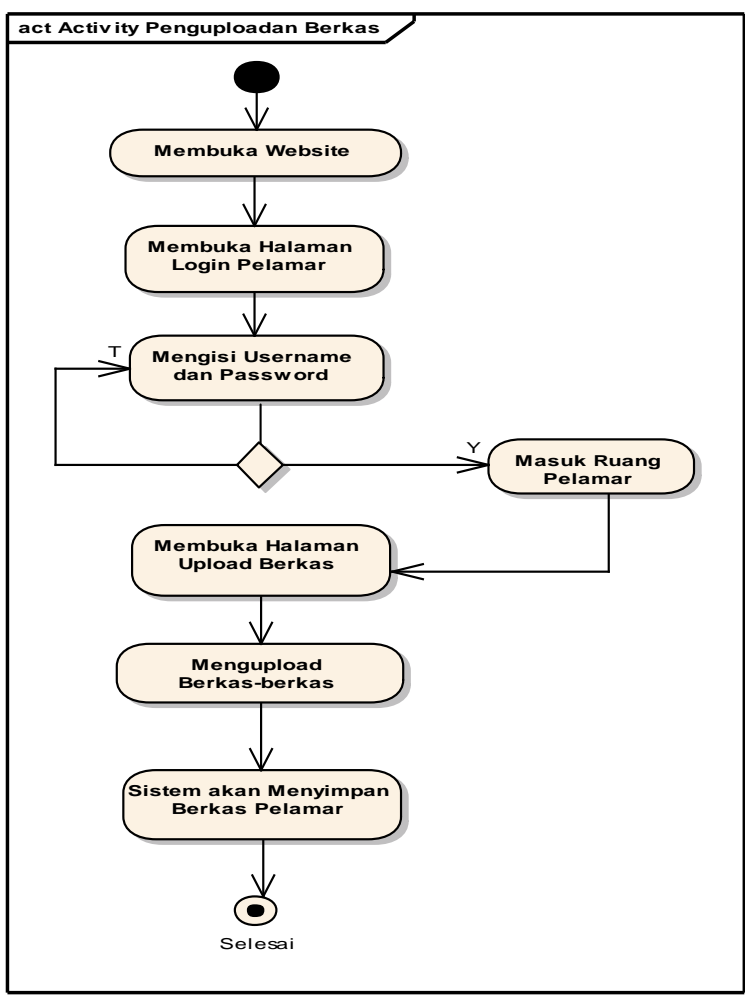

3. Activity Diagram pesikotes user

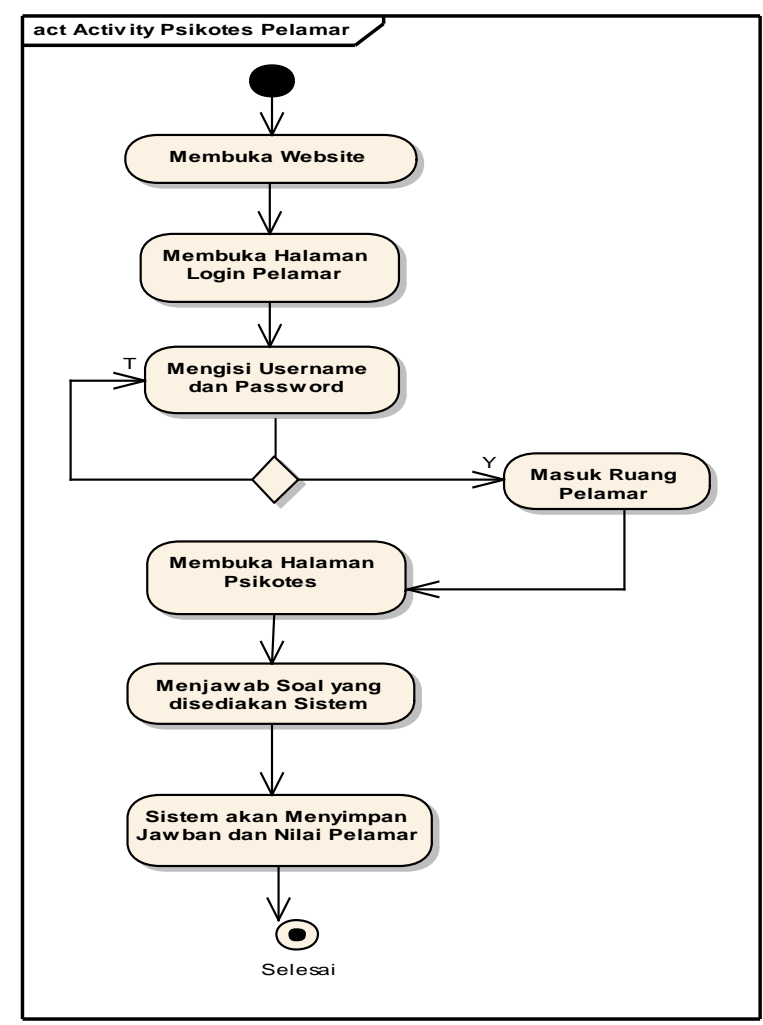




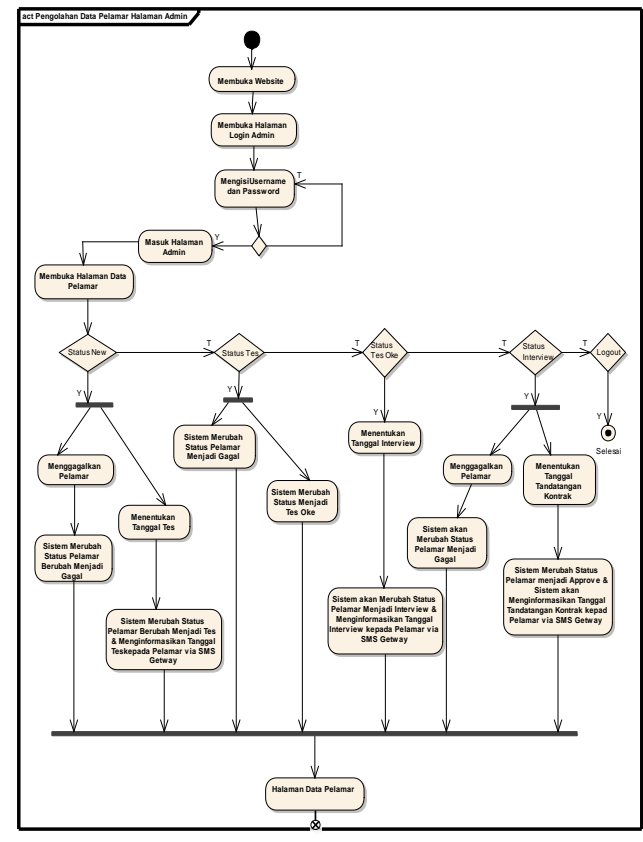

3.4. Entity Relationship Diagram

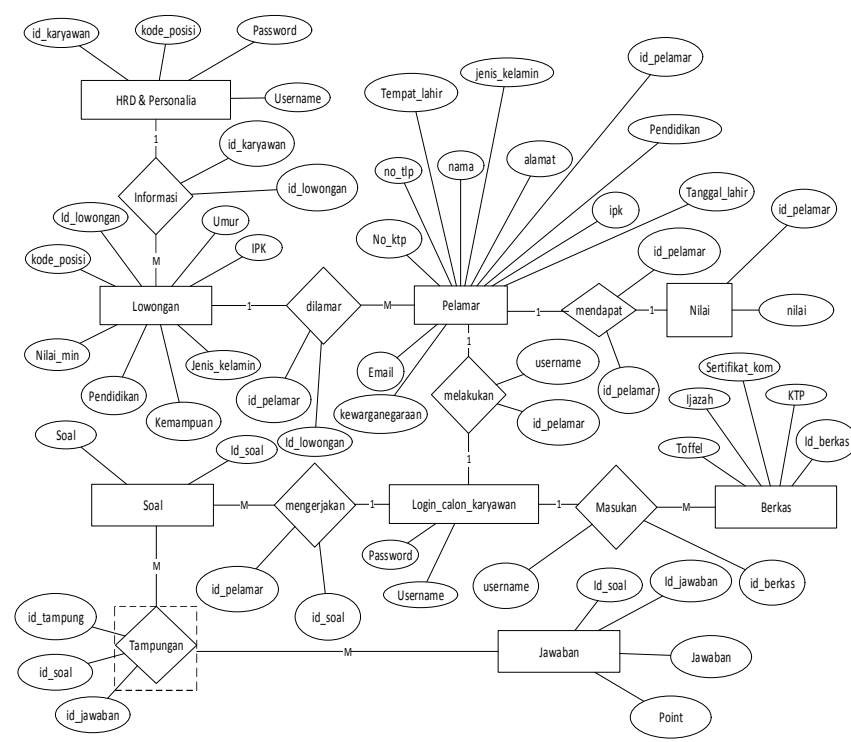

3.5. Logical Record Structure

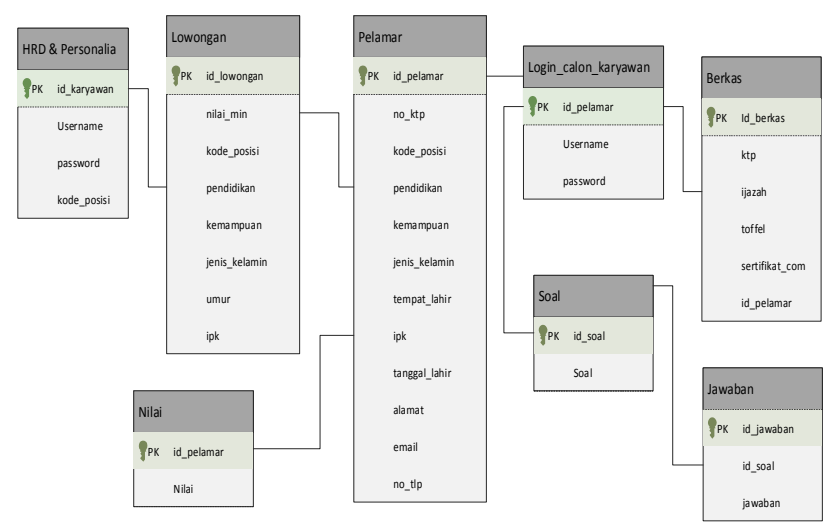

IV. HASIL TAMPILAN WEBSITE
1. Halaman Beranda

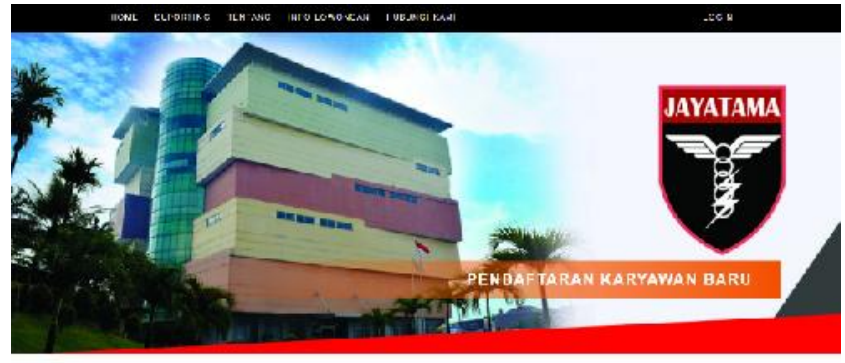

2. Halaman Supporting

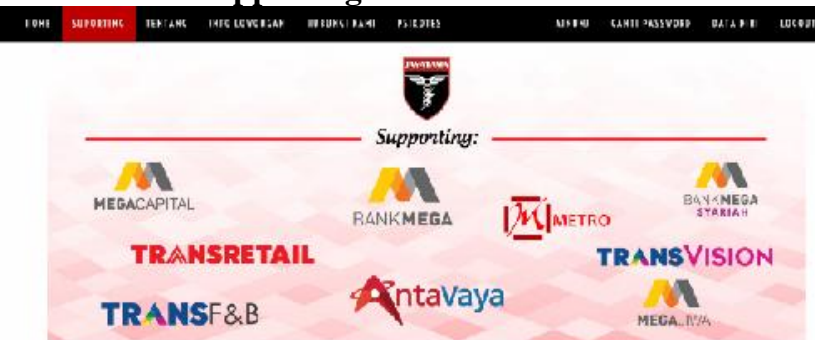

3. Halaman CAlon Pendaftaran Karyawan

PENDAFTARAN KARYAWAN

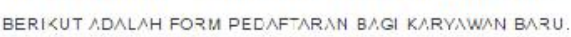
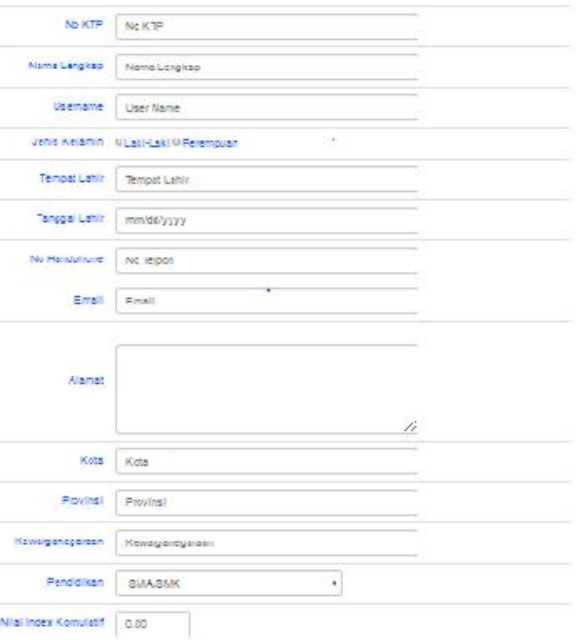

DAFTAR

4. Halaman Login Calon Karyawan

LOGIN CALON KARYAWAN
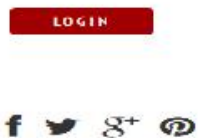

RT .IAYATAMA GPOO17

5. Halaman Penguplodan berkas 


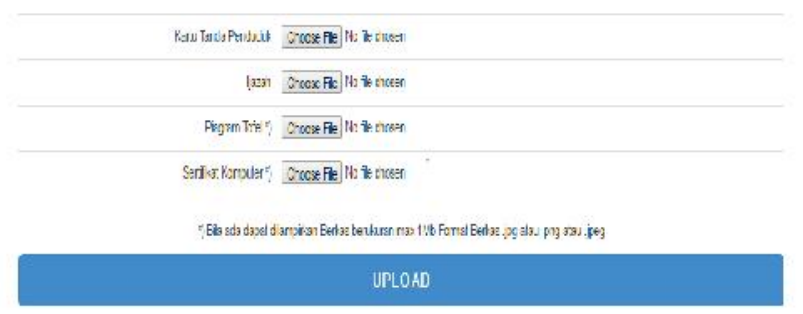

\section{Halaman Psikotes}
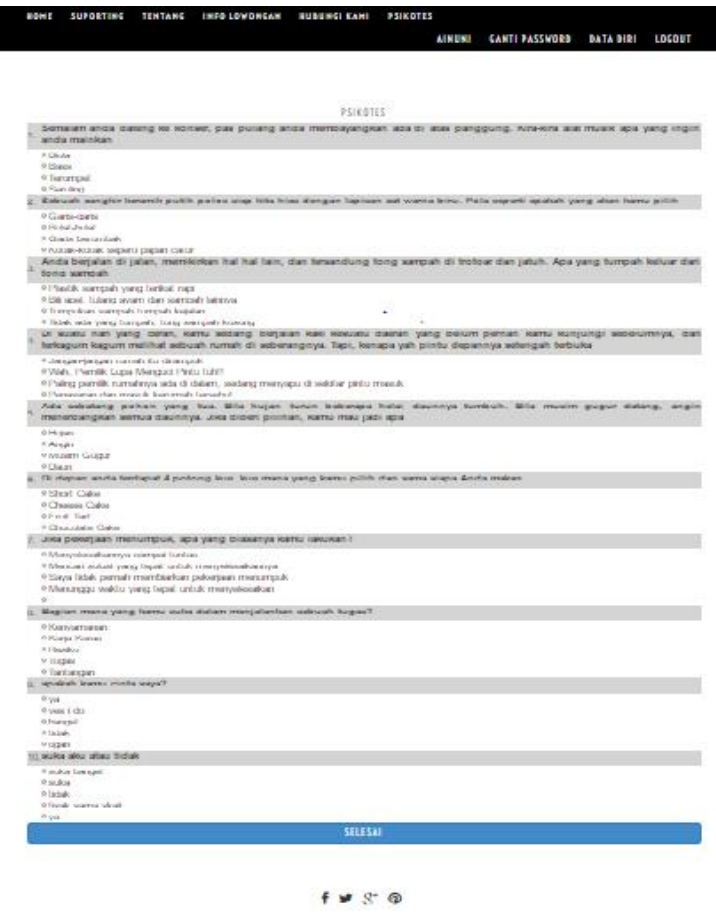

7. Halaman Admin
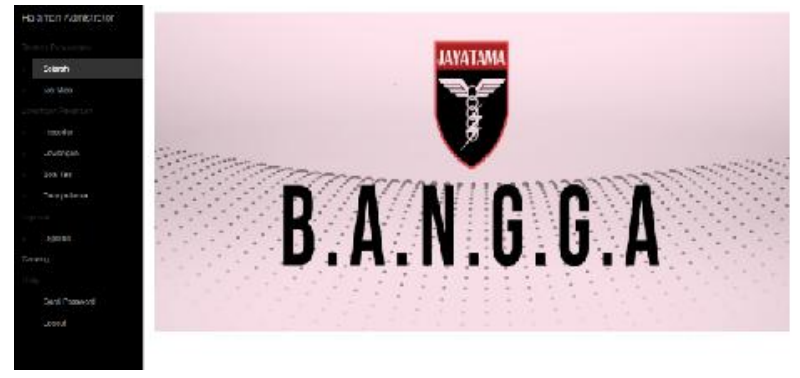

8. Halaman Tambah Psikotes

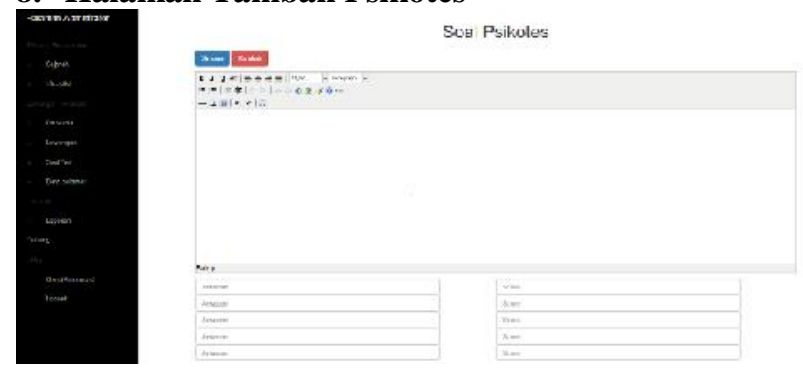

\section{KESIMPULAN}

1. Dengan perekrutan karyawan dilakukan secara online mempermudah bagian HRD dan Personalia dalam membaca data para pelamar.

2. Dalam hal penyimpanan data dapat menghemat tempat dan waktu, memudahkan pencarian.

3. Biaya yang dikeluarkan oleh perusahaan untuk proses perekrutan karyawan menjadi berkurang.

4. Waktu yang digunakan untuk melakukan proses perekrutan karyawan lebih efisien.

\section{REFERENSI}

Abdulloh, R. (2015). Web Programming Is Easy. Jakarta: Elex Media Komputindo.

Anhar. (2010). Panduan Menguasai PHP \& MySQL Secara Otodidak. Jakarta: Media Kita.

Ariani, R., \& Sukamto, M. (2015). Rekayasa perangkat lunak Terstuktur Dan Berorientasi Objek. Bandung: Informatika.

Hadi, A. (2014). Pengembangan Sistem Informasi Ujian Online Berbasis Web Dengan Pengacakan Soal Menggunakan Algoritma Fisher-Yates Shuffle. Jurnal Teknologi Informasi \& Pendidikan Vol.7 No.2 September 2014.

Indrajani. (2011). Perancangan Basis data Dalam All in 1. Jakarta: Elex Media Komputindo.

Jogiyanto, H. (2011). Analisa dan Desain Sistem Informasi. Yogyakarta: Andi Offset.

Kusrini. (2007). Strategi Perancangan dan Pengelolaan Basis Data. Yogyakarta: Andi Offset.

Nugroho, B. (2013). Dasar Pemrograman WEB PHP $M y S Q L$ dengan Dreamweaver. Yogyakarta: Gava Media.

Putri, D. L. (2014). Perancangan Sistem Informasi Penerimaan Siswa Baru Pada Sekolah Menengah Kejuruan Negeri 3 Pacitan. Indonesian Journal on Networking and Security Volume 3 No 4 Oktober 2014, 01-04.

Roviuddin. (2008). WEB PROGRAMMING (HTML, CSS, VBSCRIPT, dan. Jakarta: Mitra Wacana Media.

Sadeli, M. (2013). Toko Baju Online dengan PHP dan MySQL menggunakan. Palembang: Maxikom. 
Setyowati, W., Winarno, W. W., \& Sudarmawan.

(2015). Analisa Penerimaan Teknologi Sistem Ujian Online Untuk Meningkatkan Layanan Teknologi. Seminar Nasional Teknologi Informasi Dan Multimedia 2015 STMIK AMIKOM Yogyakarta 6-8 Februari 2015. Yogyakarta: STMIK AMIKOM Yogyakarta.

Simarmata, J. (2010). Rekayasa Perangkat Lunak. Yogyakarta: C.V ANDI OFFSET.

Supardi, Y. (2010). 16 Langkah Web Master. Jakarta: Ardikom.

Sutabri, T. (2012). Analisa Sistem Informasi. Yogyakarta: Andi Offset. 